\title{
Clinical Study to Evaluate the Efficacy and Safety of a Hair Serum Product in Healthy Adult Male and Female Volunteers with Hair Fall
}

This article was published in the following Dove Press journal: Clinical, Cosmetic and Investigational Dermatology

\author{
Muhammed Majeed ${ }^{1-3}$ \\ Shaheen Majeed (DD ${ }^{1-3}$ \\ Kalyanam Nagabhushanam (iD) ${ }^{2}$ \\ Lakshmi Mundkur (DD' \\ Prakriti Neupane ${ }^{3}$ \\ Kalpesh $\mathrm{Shah}^{3}$ \\ 'Sami Labs Limited, Bangalore, Karnataka \\ 560058, India; ${ }^{2}$ Sabinsa Corporation, \\ New Jersey, East Windsor 08520, USA; \\ ${ }^{3}$ ClinWorld Private Limited, Bangalore, \\ Karnataka, India
}

Correspondence: Kalpesh Shah ClinWorld Private Limited, 19// \& 19/2,

I Main 2nd Phase, Peenya Industrial Area, Bangalore, Karnataka 560058, India Tel +918028397973

Email kalpesh@clinworld.org
Background: Hair fall is a widespread problem among all genders, ages, and ethnicity with both physical and psychological effects.

Objective: This clinical study was designed to evaluate the efficacy and safety of a hair serum formulation containing amla extract, freeze-dried coconut water, and the micronutrient selenium along with sandalwood odorant and peanut shell extract in healthy male and female volunteers with hair fall.

Methods: A total of 42 subjects were enrolled and completed the study and they used the test product daily for 90 days. TrichoScan ${ }^{\circledR}$ was used to evaluate the efficacy of the test product for improving hair growth rate, hair density, anagen hair, telogen hair, and the density of vellus and terminal hair. Hair thinning and hair fall reduction were compared to its basline by both dermatologists and subject self-assessment questionnaires.

Result and Discussion: After 90 days of test product application, there was a significant improvement in hair growth rate $(<0.0001)$, hair density $(<0.0001)$, vellus hair density $(<0.0001)$, and terminal hair density $(<0.0001)$ in comparison to baseline. There was a significant reduction in hair fall with bulb $(<0.0001)$ and without bulb $(<0.0001)$, and hair thinning $(<0.0001)$ compared to the baseline measurement. Adverse events were not recorded during the study. No skin intolerance was reported during the study, and the test product was considered dermatologically safe to use.

Keywords: anti-hair fall serum, hair growth, TrichoScan ${ }^{\circledR}$, hair follicles, Saberry ${ }^{\circledR}$, $\operatorname{Cococin}^{\circledR}$, PeptiSeLect ${ }^{\circledR}$, sandalwood odorant, Cosmoperine ${ }^{\circledR}$

\section{Introduction}

Hair loss is a universal distressing condition involving genetic, nutritional, medical, and environmental factors. Androgenic alopecia or male-pattern baldness is the most common cause of hair loss in men, while medical conditions, including hypothyroidism, oral contraceptives, nutritional deficiency cause hair loss in women. $^{1,2}$ Human beings are born with approximately 100,000 terminal hair follicles on the scalp that are predetermined to grow long and thick hair. ${ }^{3}$

Hair follows a specific repeated growth cycle with three distinct and concurrent phases, ie, anagen lasting 3 to 5 years, catagen lasting 2 to 3 weeks, and telogen lasting 3 to 4 months, followed by shedding of hair. During the telogen or resting phase, hair is released and shed, and the next cycle is initiated at any given time. ${ }^{3-9}$ Ninety percent of the hair on the healthy scalp is growing, some are undergoing involution (less than 1\%), and remaining are resting (5\% to $10 \%) .^{4-7,10}$ Shedding of 100 hair from the head a day 
is considered normal. However, a higher rate of physiological loss is a major concern across the world; because, if it remains consistently high, it may result in male or female pattern alopecia, which further leads to psychological distress. ${ }^{11-13}$ Approximately $50 \%$ of women have visible hair loss by the age of sixty, while men tend to lose hair by the age of fifty. ${ }^{14}$

Topical minoxidil for men and women and oral finasteride for only men are the only two US FDA approved medications for androgenic hair loss, though other medications like progesterone, zinc salts, azelaic acid, flutamide, spironolactone and dutasteride are in use. ${ }^{15}$ Both the medications are associated with incomplete efficacy and adverse effects. Finasteride reduces androgen potency resulting in decreased sexual desire and impotency. ${ }^{16}$ Post Finasteride depression has also been reported. ${ }^{17}$ Minoxidil, on the other hand, is associated with facial hypertrichosis and contact dermatitis. ${ }^{18}$

The National Center for Complementary and Integrative Health recently reported that more than $30 \%$ of adults resort to nonconventional treatments for hair loss. This is a billiondollar industry with close to 30.2 billion dollars being spent on hair growth products in the USA alone. ${ }^{19}$ Both topical and oral supplements based on natural products have been used extensively to treat hair loss. Vitamins, amino acids and minerals being very common options. ${ }^{20}$ Biotin has been linked to hair loss but unfortunately there are no clinical trials correlating efficacy of biotin supplementation with hair growth. ${ }^{21}$ Further, clinicians advise caution in using biotin supplement for hair loss as it can interacts with troponin, $\mathrm{N}$-terminal pro-brain natriuretic peptide tests, and interfere with thyrotropin and thyroid hormone assays, leading to misdiagnosis of thyroid levels and cardiac syndromes. ${ }^{22}$ Several herbal therapies are in market for hair loss but only few have a strong clinical backing. Thus, the need of the hour is a safe and effective product for controlling hair loss.

With the new research approaches, many new aetiologies of hair fall are being determined. ${ }^{23-25}$ Thus, the right topical cosmetics combination with a multi-targeted approach may improve hair loss and achieve faster results. Further, people often turn towards herbal extracts, which have lower side effects and better compliance. ${ }^{20}$ Hair serum (investigational product) is a hair growth formulation containing Saberry ${ }^{\circledR}$ (Emblica officinalis extract, synonymous with Phyllanthus emblica, more commonly known as Amla, standardized for $10 \% \beta$-glucogallin), Cococin ${ }^{\mathrm{TM}}$ (freeze-dried Cocos nucifera water solids) and PeptiSeLect ${ }^{\circledR} \quad(\gamma$-L-GlutamylL-selenomethionine, CAS no. 879546-05-1) in the form of water-soluble powder as active ingredients. ${ }^{26,27}$ The formulation contained peanut shell extract to prevent allergic reactions, Sandalore ${ }^{\circledR}$ (sandalwood odorant) for aroma, Cosmoperine ${ }^{\circledR}$ (Tetrahydropiperine), a natural and safe bioavailability enhancer and other accepted excipients.

E. officinalis, a traditional herb, stimulates the proliferation of dermal papilla and enhances the hair growth from its nutrients like vitamin $\mathrm{C}$, phosphorus, calcium and iron. It is also a potent inhibitor of 5-alpha reductase enzyme, which converts testosterone to dihydrotestosterone accountable for androgenic alopecia. ${ }^{28-31}$ The deficiency of Selenium, a component of more than 25 mammalian enzymes, causes the body hair loss with pseudo albinism. The isomeric selenopeptide, PeptiSeLect ${ }^{\circledR}$, improves hair growth by promoting one of the angiogenetic growth factors. ${ }^{32}$ Coconut and its products have many known health benefits, including antidandruff and anti-hair fall effects, and have been a part of hair cosmetics like shampoo and conditioners since long. ${ }^{33}$ Peanut shell extract, with its antioxidant activity, reduces the tryptophan degradation, lipid peroxidation and protein degradation, thereby protects the hair strand..$^{34,35}$

Tetrahydropiperine increases the permeability of the actives across the intracellular lipid moiety in the skin, making them more permeable and increases the membrane fluidity and affinity of drug or nutrient to the cell membrane. It also enhances the solubility of poorly soluble topical actives. $^{36,37}$

In the present study, we explored the efficacy and safety of hair serum for hair fall reduction and improved hair growth in terms of follicular density in healthy male and female subjects.

\section{Methods}

\section{Ethics and Informed Consent}

The study was conducted at MS clinical Research, Bangalore, after the ethical approval from an Independent Ethics Committee (Clinicom Ethics Committee). The study was performed in accordance with the principles stated in the Declaration of Helsinki and its subsequent amendments and the Good Clinical Practice Guideline. The trial was registered prospectively in the clinical trial registry of India (CTRI) with the registration number CTRI/2019/08/020742. Signed and dated informed consent was obtained from all the subjects before enrolment in the study.

\section{Study Design}

The study was an open-label clinical study to evaluate the efficacy and safety of hair serum in healthy adult male and 
female volunteers with self-perceived hair fall. The study included 42 subjects with an age range of 25-45 years having grade 3-6 severity of hair loss as evaluated by a photo numeric 10-point scale. Further, subjects with a hair density of more than 100 and less than 200 hair follicle per square centimeters as per TrichoScan ${ }^{\circledR}$ measurement, complaining of hair fall and hair damage, agree to refrain from using hair dye/ hair, oil treatment or spa treatment, perming or straightening were included. The study participants were non-smokers, not following crash dieting or heavy drinking and were not part of any other similar study in the past three months.

The exclusion criteria include the subjects who have undergone hair growth treatment within three months before screening, who have scalp disease which may interfere in the study, undergone chemotherapy for cancer in the last six months, and have a history of alcoholism/or psychiatric disorders including trichotillomania. The detailed subject selection criteria are available in Supplementary document 1.

The study included a total of 10 visits. The first visit (day -15) was a screening visit during which the subjects were evaluated based on the study inclusion-exclusion criteria. This visit also included the shaving of the test area. The final eligibility was confirmed with density evaluation two days after shaving (day -13). The subjects were required to answer a "Quality of Life" questionnaire on the first (day -15) and last visit (day 90).

Post-visit 1, during the two weeks of washout period, the subjects were provided with neutral shampoo to use at home and instructed not to use more than thrice a week. After two weeks of washout period, baseline assessments were performed (day 0), and subjects were given the test product. And they were instructed to use the test product, 2 $\mathrm{mL}$ (male) to $3.5 \mathrm{~mL}$ (female) once daily at night by partitioning the hair into parts as a leave in serum for three (3) months. Also, they were instructed to continue with the use of neutral shampoo. Follow-up evaluation was performed during the treatment phase at the end of every month for three months.

The efficacy of the test product for improvement in hair growth, hair density, anagen hair, telogen hair, the density of vellus hair and terminal hair was evaluated by TrichoScan $^{\circledR} \quad$ (Trichoscan Professional V3.7.27.124, Tricholog $\mathrm{GmbH} \&$ Datinf $\mathrm{GmbH}$ ). Two days before each assessment visit, the subjects were called for shaving of the assessment area.

The measurement site was selected such that hair in the close vicinity is combed for shaving two fingers away from the parting or on the receding hairline of the frontotemporal regions or on the vertex. The mask was applied, and hair were pulled through it and shaved leaving neat space of $1 \mathrm{~cm}^{2}$. Dye was applied to the masked surface area and cleansed after 15 minutes with alcohol-based solution. Images were taken using camera, placing the lens by pressing into the wet assessment area such that no bubbles were trapped. The recorded images were loaded into Trichoscan software which automatically proceeds with the analysis. The same area was identified and assessed in the follow-up visits.

MSCR 10-point photo numeric linear scale was used to grade the hair fall severity and it is the extended form of Norwood and Ludwig scale for Indian male and female respectively, which is more sensitive in clinical practice. We also used Norwood scale for male and Ludwig scale for female at baseline and final visit to co-relate the MSCR scale.

Dermatologist evaluated the parameters like hair thinning and hair fall reduction with hair comb test, and hair pull test. The subject's hair and scalp quality were evaluated with the subject self-assessment questionnaire. Improvement in subjects' quality of life was measured using quality-of-life questionnaires at screening and final visits. The study product's safety was evaluated based on the occurrence of adverse events, both by subject and the dermatologist.

\section{Statistical Analysis}

A sample size of forty-two subjects were used for the statistical analysis. Continuous data are presented as mean and standard deviation while, for categorical data, the frequency and percentage are presented. The efficacy parameters were compared from baseline to the end of treatment. A p value was measured between screening and end of the treatment over SAQ domain, using the non-parametric Wilcoxon signed rank test. Two-tailed Student's $t$-test was used for the comparison of quantitative variables (age, hair fall reduction, improved hair growth and hair thickness). Paired $t$-test was used to evaluate the efficacy of the product.

\section{Results}

\section{Demographics and Baseline Characteristics}

This study was a monocentric clinical trial to investigate hair serum $2 \mathrm{~mL}$ to $3.5 \mathrm{~mL}$ once daily in the night. Fortytwo healthy adult male (21) and female (21) volunteers with hair fall were enrolled and completed the study out of 46 screened subjects wherein, one was deemed a screen failure and the other three were lost to follow-up (Table 1). 
Table I Patient Characteristics and Baseline Demographics

\begin{tabular}{|l|l|}
\hline Parameters & $\begin{array}{l}\text { Hair Serum }(\mathbf{n}=42) \text { Male Subjects: } \\
\text { 2mL, Female Subjects: 3.5mL }\end{array}$ \\
\hline $\begin{array}{l}\text { Age, years } \\
\text { Mean (SD) } \\
\text { Range }\end{array}$ & $\begin{array}{l}37.3(5.06) \\
25-45\end{array}$ \\
\hline $\begin{array}{l}\text { Gender category, } \mathbf{n}(\%) \\
\text { Male } \\
\text { Female }\end{array}$ & $21(50)$ \\
\hline $\begin{array}{l}\text { Race category, } \mathbf{n}(\%) \\
\text { Asian-Indian heritage }\end{array}$ & $42(100)$ \\
\hline $\begin{array}{l}\text { Hair density } \\
>100 \text { and }<200\end{array}$ & TrichoScan ${ }^{\circledR}$ measurement \\
$\begin{array}{l}\text { as per } \\
42(100)\end{array}$ & \\
\hline
\end{tabular}

Abbreviations: $n$, number of subjects; SD, standard deviation.

\section{Efficacy}

\section{Dermatological Assessment}

\section{Hair Comb Test}

The results of Dermatological assessment for Comb Test for hair fall with bulb and without bulb were noted to be significantly less at Day 60 and Day 90 compared to baseline. The percentage reduction was $57.53 \%$ and $81.60 \%$ respectively for hair fall with bulb and hair fall without bulb at the end of the study (Figure 1).

\section{Hair Thinning}

Hair thinning was improved significantly at both Day 60 and Day 90 over baseline. Test product showed an improvement of $7.03 \%$ and $17.55 \%$ in hair thinning at Day 60 and Day 90, respectively, compared to baseline (Figure 2).

\section{Hair Fall Test}

There was no significant difference noted in hair fall based on linear photo numeric scale at all-time points compared to baseline (Figure 3A). The grading in thirty-eight subjects remained constant while the grading for three subjects increased from 3 to 4 and for one subject, it improved from 6 to 4 .

\section{Hair Pull Test}

Hair pull test is used to determine how tightly hair is anchored to the hair papilla. The mean number of hairs removed per pull significantly reduced from 2.27 to 1.33 $(41.4 \%)$ at the end of the study compared to baseline.
Statistically significant change was noticed as early as day 30 (Figure 3B).

\section{Instrument Assessment}

Hair Density by TrichoScan ${ }^{\circledR}$

Statistical analysis of the mean hair density rate measured by TrichoScan ${ }^{\circledR}$ in the test product showed a significant improvement as early as 30 days and at all-time points compared to baseline (Figure 4A). The density increased from $171.35 \pm 21.9$ per $\mathrm{cm}^{2}$ to $185.01 \pm 20.57$ per $\mathrm{cm}^{2}$ resulting in a percentage change of $7.97 \%$.

\section{Hair Growth Rate by TrichoScan ${ }^{\circledR}$}

With the continuous application of test product, significant improvement was noted in hair growth rate at day 30, day 60 and 90 compared to baseline. The mean growth rate improved from 306.39 to $359.56 \mu \mathrm{m} / 2$ days resulting in $17.36 \%$ change (Figure 4B).

\section{Anagen and Telogen \% by TrichoScan ${ }^{\circledR}$}

The percentage of anagen and telogen was maintained similar throughout the study period; however, there was no decline in the mean percentage (Figure 4C).

\section{Vellus and Terminal Density by TrichoScan ${ }^{\circledR}$}

The assessment for vellus and terminal density is performed on the TrichoScan ${ }^{\circledR}$ Software. There was a statistically significant improvement noted in terminal density at all-time points compared to baseline (Figure 4D). There was a percentage change of 13.51 and 5.93 in vellus and terminal hair density respectively at visit 10 compared to baseline.

\section{Subject Self-Assessment Questionnaire}

Subject self-assessments were perceived as statistically significant improvements in overall hair fall rate, hair texture, hair volume, and scalp itching at all time-points of the study compared to baseline. It was noted that there was no itching recorded after visit 8 (Day 60) and with the continuous application of the test product, hair fall stopped at Day 90 (Table 2).

\section{Quality of Life Questionnaire}

Subjects were asked to complete the quality of life questionnaire at screening and final visit. The quality of life improved in $90-100 \%$ of the subjects based on six questionnaires related to the hair fall and its impact on daily life events (Table 3). 


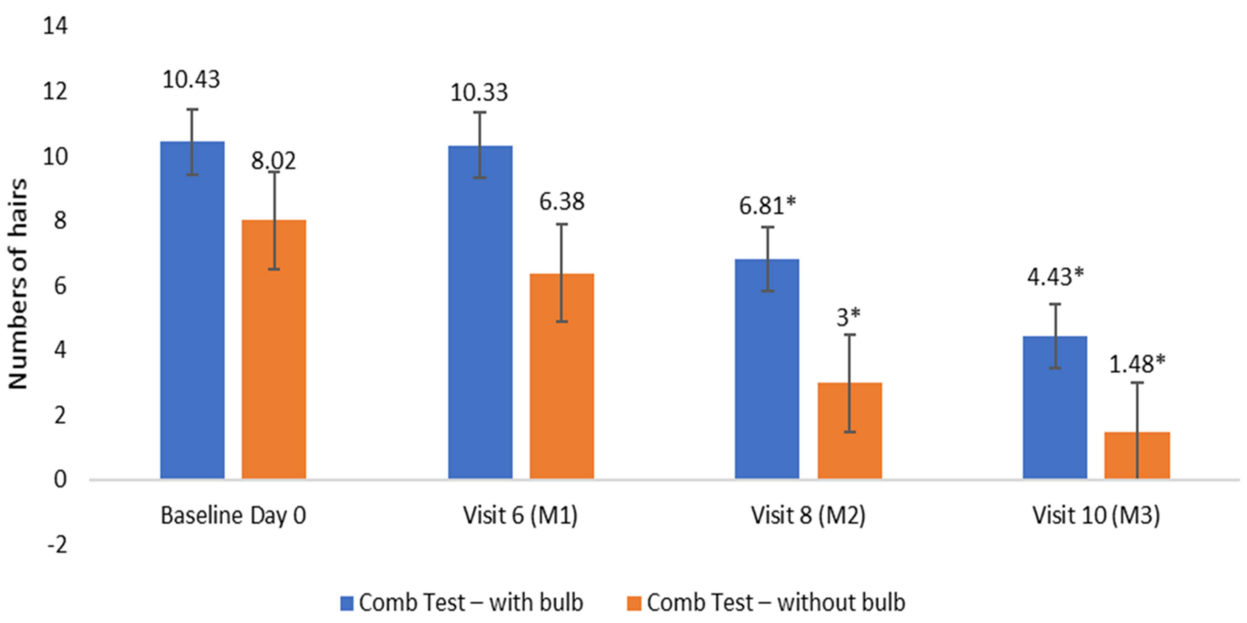

Figure I Dermatological assessment for Comb Test. Number of hairs collected after the hair comb test were counted and separated as hair fall with bulb and hair fall without bulb at visit I, visit 6, visit 8 and visit 10; Values are expressed in Mean $\pm \mathrm{SE}$; ${ }_{p}<<0.05$ by $t$-test.

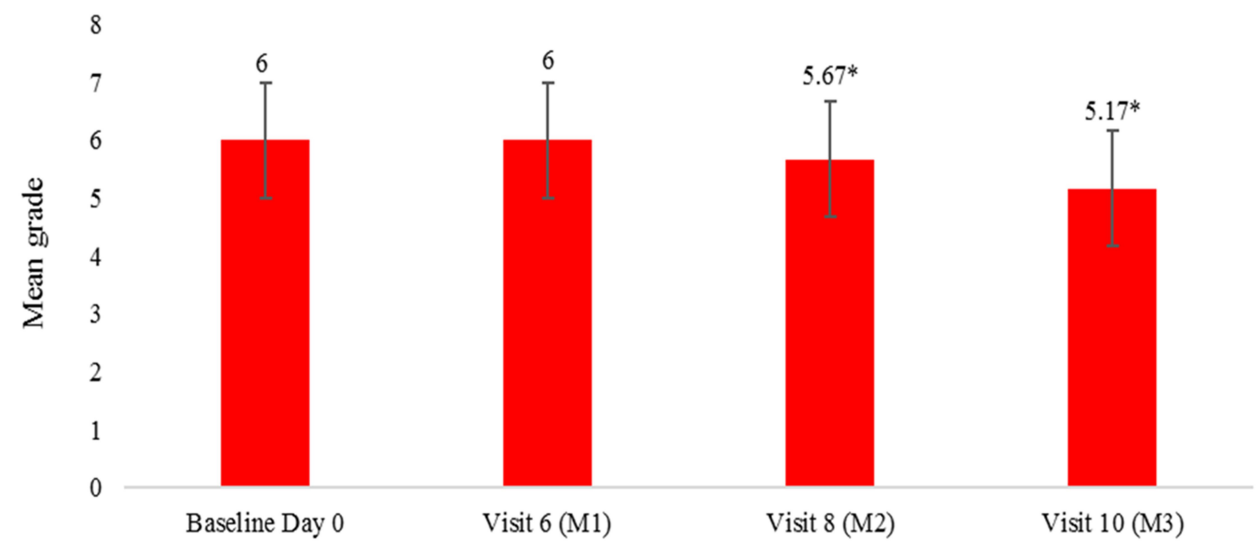

Figure 2 Hair Thinning evaluation by Image comparison. Hair fall was measured using MSCR I0-point photo-numeric hair thinning scale which was compared with the image taken from VISIA CR imaging, lower the grade better the result, values are expressed as Mean \pm SE, ${ }^{*} p<0.05$ by $t$-test.

A

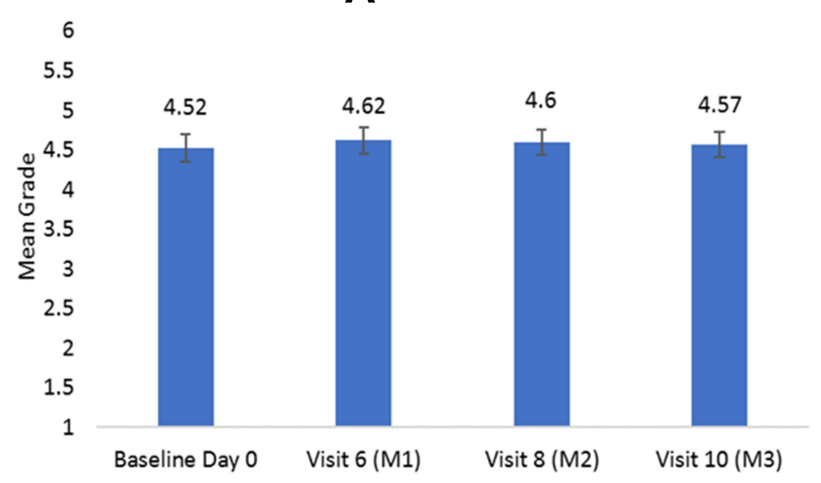

B

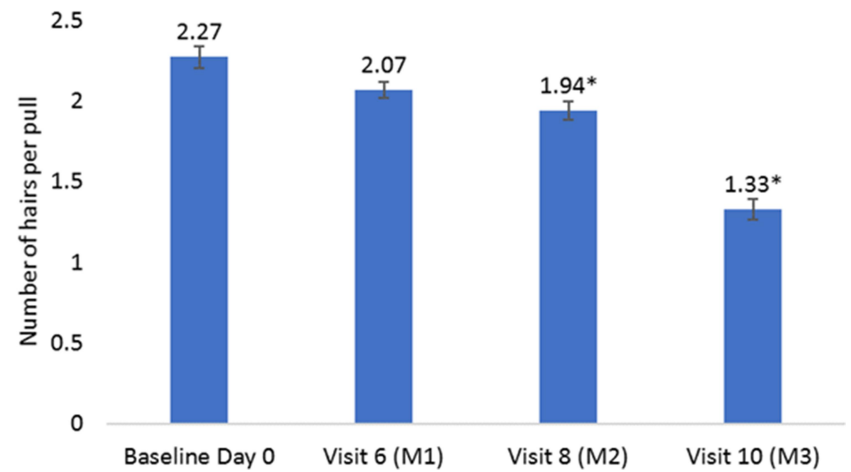

Figure 3 (A) Hair fall assessment by linear photo numerical scale. Hair fall was assessed using MSCR I0-point photo-numeric hair thinning scale compared with the scalp of the subjects directly during their study visits; Lower the value better the result; values are expressed as mean grade \pm SE. (B) Hair pull test assessment results. Hair was firmly tugged away from the scalp as fingers slide along the hair shaft and the number of extracted hairs were counted. Values are expressed as mean number of hairs per pull $\pm \mathrm{SE}, * p<0.05$ by $t$-test. 
A

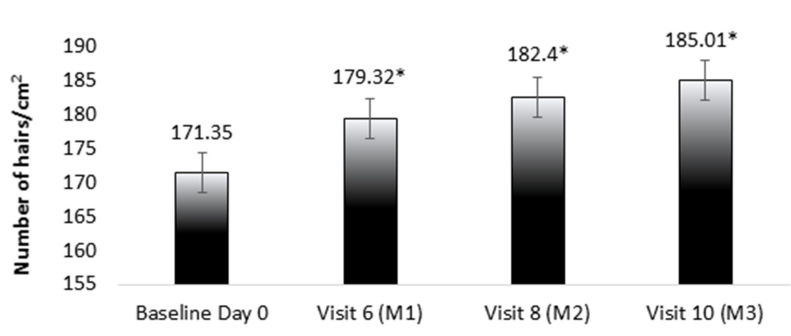

C

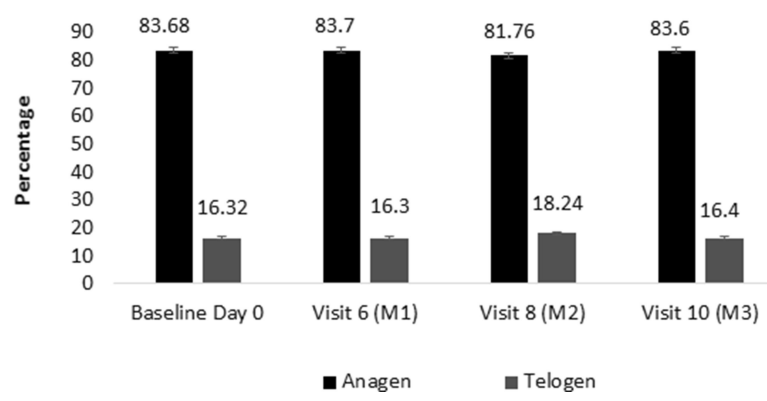

B

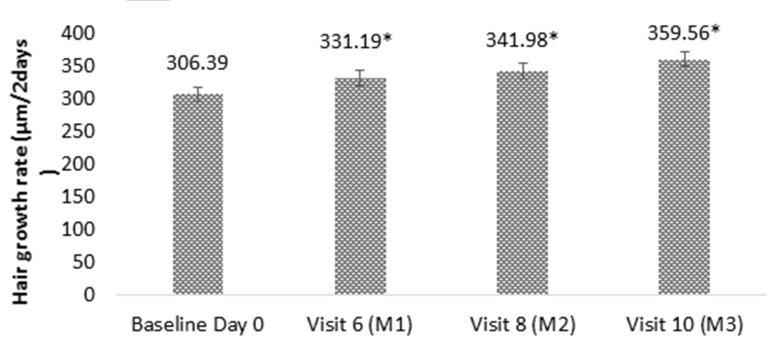

D

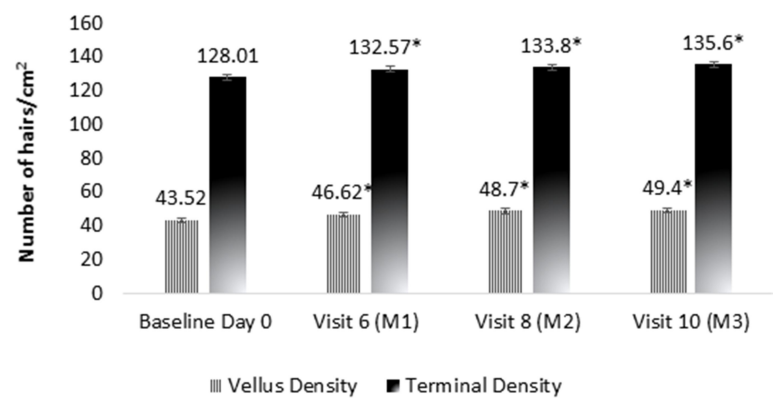

Figure 4 TrichoScan ${ }^{\circledR}$ Assessment in $\mathrm{I} \mathrm{cm}^{2}$ shaved area of the scalp. (A) Assessments of hair density as number of hairs per $\mathrm{cm}^{2}$. (B) Assessments of Hair Growth rate as length of hair grown per 2 days. (C) Assessment of anagen and telogen \%. (D) Density of terminal and vellus hair as the number of hairs per $\mathrm{cm}^{2}$. Values are expressed as mean $\pm \mathrm{SE} ; * p<0.05$ by $t$-test.

\section{Secondary Outcomes}

\section{Safety}

There were no adverse events or serious adverse events reported during the conduct of the study. However, hair and scalp conditions like itching, dryness, and dandruff, which were captured as part of 'Subjects Self-Assessment and Dermatological Assessments' during the baseline visit, were resolved after application of the product. None of the subjects experienced erythema, allergic reactions, folliculitis, oiliness, burning, and boils on the scalp during the course of the study.

\section{Discussion}

The present study shows that the hair serum formulation containing freeze-dried coconut water, amla extract, a selenopeptide, sandalwood odorant, peanut shell extract and tetrahydropiperine as key ingredients that increases hair density and potentiates hair growth in both male and female volunteers that are experiencing hair fall. Freeze-dried coconut water is the powerhouse of micronutrients and growth promoters that help in promoting hair growth. ${ }^{26}$ Amla extract stimulates hair growth and makes hair softer and shinier. ${ }^{30}$ Tetrahydropiperine is a scientifically validated, non-irritant

Table 2 Changes in Self-Assessment Questionnaire, Mean (SD)

\begin{tabular}{|l|l|l|l|l|}
\hline Product (N=42) & Baseline Day 0 & Visit 6 (MI) Day 30 & Visit 8 (M2) Day 60 & Visit 10 (M3) Day 90 \\
\hline Hair fall rate & $2.62(0.62)$ & $3.36(0.76)$ & $4.33(0.75)$ & $4.74(0.45)$ \\
Hair texture & $2.57(0.59)$ & $2.93(0.4 I)$ & $3.17(0.38)$ & $3.69(0.47)$ \\
Hair volume & $2.7 \mathrm{I}(0.5 \mathrm{I})$ & $2.83(0.44)$ & $2.95(0.44)$ & $3.02(0.52)$ \\
Grading hair fall & $1.52(0.5 \mathrm{I})$ & $0.43(0.7)$ & $0.02(0.15)$ & $0(0)$ \\
Scalp itching & $0.8 \mathrm{I}(0.59)$ & $0.05(0.3 \mathrm{I})$ & $0(0)$ & $0(0)$ \\
\hline
\end{tabular}

Notes: N, number; SD, standard deviation; M, month; hair fall rate: I = more than 100 (worst possible condition), 2= 50-100, 3= 30-50, 4= $10-30,5=1$ less than 10 (best possible condition); hair texture: I = rough and frizzy (worst possible condition), 2= rough, 3= normal, 4= soft, $5=$ very soft (best possible condition); hair volume score: I= very less volume (worst possible condition), $2=$ less volume, $3=$ average, $4=$ good volume, $5=$ excellent (best possible condition); grading hair fall: $0=$ no itching (best possible condition), I= negligible itching-no concern, $2=$ mild itching, $3=$ moderate itching, $4=$ severe itching, $5=$ very severe itching-compromises the daily routine. 
Table 3 Quality of Life Questionnaire (Change from Baseline to Final Visit)

\begin{tabular}{|l|l|l|l|l|l|l|l|l|l|l|}
\hline \multirow{2}{*}{ Questions } & \multicolumn{4}{|l|}{ Visit I (Baseline) } & \multicolumn{3}{l|}{ Visit 10 (Final Visit) } \\
\cline { 2 - 10 } & Often & Sometimes & Rarely & Always & Never & Often & Sometimes & Rarely & Always & Never \\
\hline Q1 & $6(14.29 \%)$ & $24(57.14 \%)$ & $7(16.67 \%)$ & $5(11.9 \%)$ & $0(0 \%)$ & $0(0 \%)$ & $0(0 \%)$ & $4(9.52 \%)$ & $0(0 \%)$ & $38(90.48 \%)$ \\
Q2 & $10(23.81 \%)$ & $24(57.14 \%)$ & $3(7.14 \%)$ & $5(11.9 \%)$ & $0(0 \%)$ & $0(0 \%)$ & $0(0 \%)$ & $4(9.52 \%)$ & $0(0 \%)$ & $38(90.48 \%)$ \\
Q3 & $13(30.95 \%)$ & $20(47.62 \%)$ & $2(4.76 \%)$ & $7(16.67 \%)$ & $0(0 \%)$ & $0(0 \%)$ & $0(0 \%)$ & $0(0 \%)$ & $0(0 \%)$ & $42(100 \%)$ \\
Q4 & $10(23.81 \%)$ & $22(52.38 \%)$ & $9(21.43 \%)$ & $1(2.38 \%)$ & $0(0 \%)$ & $0(0 \%)$ & $0(0 \%)$ & $0(0 \%)$ & $0(0 \%)$ & $42(100 \%)$ \\
Q5 & $5(11.9 \%)$ & $29(69.05 \%)$ & $2(4.76 \%)$ & $6(14.29 \%)$ & $0(0 \%)$ & $0(0 \%)$ & $0(0 \%)$ & $0(0 \%)$ & $0(0 \%)$ & $42(100 \%)$ \\
Q6 & $16(38.1 \%)$ & $17(40.48 \%)$ & $4(9.52 \%)$ & $5(11.9 \%)$ & $0(0 \%)$ & $0(0 \%)$ & $0(0 \%)$ & $2(4.76 \%)$ & $0(0 \%)$ & $40(95.24 \%)$ \\
\hline
\end{tabular}

Notes: Values are expressed as the number of subjects responded for each category and percentage of subjects in parenthesis. QI: Do you feel uncomfortable, frustrated, or stressed because of your hair fall? Q2: Do you feel that your physical appearance has deteriorated due to your hair fall, and do you look in the mirror too often or avoid looking in the mirror entirely? Q3: Do you feel uncomfortable when people in the community ask you about your hair fall? Q4: Do you avoid your friends or refrain from attending social situations because of your hair fall? Q5: Do you get desperate thinking that your hair fall will never improve? Q6: When treating your hair fall, have you ever thought that you are just wasting time and money?

dermal penetration enhancer with no known side effects. It does not modify the physical properties of cosmetic formulation and is usually compatible with most of the topical formulation bases. ${ }^{36}$ Peanut shell extract prevents itching and allergy, while selenopeptide helps in hair growth and prevents hair loss. ${ }^{34,38}$ Thus, hair serum containing these ingredients provided the therapeutic benefits in preventing hair fall and promoting hair growth in human volunteers. The formulation did not contain parabens, formaldehyde, and synthetic dyes; therefore, it is mild, safe, and gentle on the scalp.

Hair fall is a common and stressful symptom, distressing the quality of life of an individual. It affects a huge percentage of the population, including both male and female. $^{3,39}$ Treating hair fall or hair loss is necessary, considering its psychosocial complications such as anxiety and depression. ${ }^{16}$

The traditional medicinal systems have used herbal therapies to treat alopecia since ancient time. More than a thousand plant species have been studied for their benefit in hair care. Rosemary oil, Grape seed extract, Hibiscus rosasinensis, Sage, and Nettles reduce hair fail due to the increased blood flow. Ginkgo biloba, Emu oil and Green tea extracts are known to inhibit 5-alpha reductase, thus reducing dihydrotestosterone and are considered possible alternative treatments for alopecia. ${ }^{40} \mathrm{~A}$ combination of $\beta$ glucogallin (found in Emblica officinalis extract), selenopeptide and freeze-dried coconut water have a combined effect in protecting dermal papilla. ${ }^{29}$ The current clinically evaluated novel hair serum formulation includes the ingredients which have been studied for the treatment of alopecia with various mechanisms to reduce hair fall and promote hair growth.

Several preclinical and in vitro studies have described the role of vascular endothelial growth factor (VEGF) in promoting hair growth by increased proliferation of cells surrounding the hair follicles. ${ }^{41}$ The isomeric peptide obtained by L-selenomethionine's linkage with L-glutamic acid possesses enhanced purity, aqueous solubility, stability and bioavailability with acceptable odor, unlike other selenium compounds. It promotes the VEGF activity and inhibits the 5-alpha reductase activity resulting in reduced hair fall and increased hair growth while maintaining the homeostasis of the hair cycle. ${ }^{38}$ Traditionally E. officinalis powder was used as a hair tonic and also for shampooing and for preventing premature hair greying. ${ }^{42}$ Several phytoconstituents such as alkaloids, terpenoids, flavonoids, pectin, saponins, tannins, ascorbic acids, carbohydrates and many other compounds are existing in the fruit of the plant which nourishes the hair. ${ }^{43}$ In addition, it possesses antibacterial and antioxidant activity, which further prevents hair fall as a result of infections. ${ }^{44}$ A clinical study of herbal products containing E. officinalis extracts helped slow the progression of hair loss and enhance hair growth over sixteen weeks. ${ }^{31}$ In the present study, we observed a $57.53 \%$ reduction in hair fall with bulb and $81.60 \%$ reduction in hair fall without bulb by the end of the study. A reduction in hair breakage was observed at all time-points, which implies that test product improves the tensile strength of the hair.

Hair fall is a multifactorial condition, which is affected by nutritional factors. Recent studies suggest that micronutrient supplements help to reduce hair shedding. ${ }^{45}$ Coconut has a property to condition hair, prevent split ends, reduce frizz, control flaky scalp, and dandruff. ${ }^{33}$ In a previous study, freezedried coconut water in comparison to minoxidil showed better improvement in the anagen-telogen hair ratio. ${ }^{46}$ In another study, three months of treatment with a lotion containing sandalwood odorant was effective in hair fall reduction and the promotion of hair growth with an increase in hair density, hair shaft diameter, percentage of anagen hair, and mass hair 
index. ${ }^{47}$ In the present study, there was no significant change in the anagen-telogen ratio; however, a significant improvement in hair density, hair growth rate, vellus, and terminal density was observed as measured by TrichoScan ${ }^{\circledR}$ at all timepoints of the study in comparison to baseline. The change in hair density was proportional to the image-based evaluation of hair thinning, higher the hair density, lower was the grade in the scale. In a study with androgenic alopecia patients finasteride improved the hair counts by $9.2 \%$ in comparison to placebo at 48 weeks ${ }^{48}$ whereas our study product improved the follicular hair density by $7.97 \%$ at week 8 in comparison to baseline suggesting its efficacy for hair fall control similar to the standard therapy. The subjects agreed with the hair progressive growth rate improvement as measured by TrichoScan $^{\circledR}$, in the self-assessment questionnaire. Also, subjects experienced significant improvement in hair texture and hair volume as assessed by a self-assessment questionnaire at all visits of the study compared to baseline.

Luteolin is one of the major constituents of peanut shell extract, having anti-allergic effects and antiinflammatory effects. ${ }^{49,50}$ In this study, the test product was observed to be effective against dryness. Scalp itching significantly reduced at all time-points with no itching recorded after day 60 of the treatment indicating its effectiveness in the hair fall even in the dry and itchy scalp.

This study's limitations include the small sample size and open-label single-arm, non-comparative study design. Further, the study with the larger sample size, longer duration, and wider population range in a comparative study design can add up the scientific value to our clinical study.

\section{Conclusion}

Thus, this novel hair serum could be a safe alternative to manage hair thinning and induce hair growth. It is free of parabens, formaldehyde, and synthetic dye, rendering it a mild, safe, and gentle product on the scalp. Overall, test product was effective in controlling hair fall in more than $98 \%$ of the study population with the $7.97 \%$ increase in the follicular hair density. There was an improvement in hair fall-related quality of life in the majority of the subjects at the end of the study. The subject feedback on the product color, fragrance, texture, and effects in hair fall was highly positive. There were no adverse event recorded throughout the study, related to the study product; which implies that the test product is safe to use topically. The results of this study showed that the application of the Hair Serum formulation on healthy male and female volunteers with hair fall condition for a treatment period of three months was safe and effective.

\section{Data Sharing Statement}

All relevant (deidentified participant data) is made available in the manuscript and we do not have a separate repository.

\section{Acknowledgments}

We would like to thank clinical trial investigators Dr. Sapna R and Dr. Mukesh Ramnane, and MS Clinical Research Pvt. Ltd. team, Bangalore, India.

\section{Disclosure}

The authors declare that this study received funding from Sami Labs Limited/Sabinsa Corporation. The funder was involved in conceptualizing the project and providing resources. The funder was not involved in study design, data collection, and analysis of results, but was part of reviewing the manuscript and decision to publish. All the authors are affiliated with Sami Labs Limited or Sabinsa Corporation or ClinWorld Private Limited. Dr Muhammed Majeed and Dr Kalyanam Nagabhushanam have patents US 9,681,665, US 9,681,666, US 9,635,862, and US 9,596,861 related to the present study. The authors report no other potential conflicts of interest for this work.

\section{References}

1. Harrison S, Bergfeld W. Diffuse hair loss: its triggers and management. Cleve Clin J Med. 2009;76(6):361-367. doi:10.3949/ ccjm.76a.08080

2. Thiedke CC. Alopecia in women. Am Fam Physician. 2003;67 (5):1007-1014.

3. Price VH. Treatment of hair loss. $N$ Eng J Med. 1999;341 (13):964-973. doi:10.1056/NEJM199909233411307

4. Sinclair R. Male pattern androgenetic alopecia. BMJ. 1998;317 (7162):865-869. doi:10.1136/bmj.317.7162.865

5. Blume U, Ferracin J, Verschoore M, Czernielewski J, Schaefer H. Physiology of the vellus hair follicle: hair growth and sebum excretion. Br j Dermatol. 1991;124(1):21-28. doi:10.1111/j.13652133.1991.tb03277.x

6. Messenger A, Dawber R. The Physiology and Embryology of Hair Growth. Diseases of the Hair and Scalp. 3rd ed. Oxford, England: Blackwell Science; 1997:1-22.

7. Orasan MS, Roman II, Coneac A, Muresan A, Orasan RI. Hair loss and regeneration performed on animal models. Clujul Med. 2016;89 (3):327.

8. Uno H. Biology of hair growth.Seminars in Reproductive Endocrinology. 1986;4(2):131- 141. doi:10.1055/s-2007-1022494.

9. Montagna W, Parakkal PF. 1 - An Introduction to Skin. In: Montagna W, Parakkal PF, editors. The Structure \& Function of Skin. Third ed. Academic Press; 1974:1-17.

10. Abell E. Embryology and anatomy of the hair follicle. Dis Hair Growth. 1993;1-19. 
11. Whiting DA. Chronic telogen effluvium. Dermatol Clin. 1996;14 (4):723-731. doi:10.1016/S0733-8635(05)70398-3

12. Alfonso M, Richter-Appelt H, Tosti A, Viera MS, García M. The psychosocial impact of hair loss among men: a multinational European study. Curr Med Res Opin. 2005;21(11):1829-1836. doi:10.1185/030079905X61820

13. Cash TF, Price VH, Savin RC. Psychological effects of androgenetic alopecia on women: comparisons with balding men and with female control subjects. J Am Acad Dermatol. 1993;29(4):568-575. doi:10.1016/0190-9622(93)70223-G

14. Whiting DA. Male pattern hair loss: current understanding. Int J Dermatol. 1998;37(8):561-566. doi:10.1046/j.13654362.1998.00542.x

15. Schweiger ES, Boychenko O, Bernstein RM. Update on the pathogenesis, genetics and medical treatment of patterned hair loss. J Drugs Dermatol. 2010;9(11):1412-1419.

16. Khalid AA. Medical Treatment of Alopecia. In: Ahmad M, editor. IntechOpen. 2018:55.

17. Mella JM, Perret MC, Manzotti M, Catalano HN, Guyatt G. Efficacy and safety of finasteride therapy for androgenetic alopecia: a systematic review. Arch Dermatol. 2010;146(10):1141-1150. doi:10.1001/archdermatol.2010.256

18. Rogers NE, Avram MR. Medical treatments for male and female pattern hair loss. $J$ Am Acad Dermatol. 2008;59(4):547-566.

19. Complementary A. Or Integrative Health: What's in a Name? $\mathrm{NCCIH}$. National Center for Complementary and Integrative Health NCCIH; 2016.

20. Hosking A-M, Juhasz M, Mesinkovska NA. Complementary and alternative treatments for alopecia: a comprehensive review. Skin Appendage Disorders. 2019;5(2):72-89. doi:10.1159/000492035

21. Soleymani T, Shapiro J. The Infatuation With Biotin Supplementation: is There Truth Behind Its Rising Popularity? A Comparative Analysis of Clinical Efficacy versus Social Popularity. J Drugs Dermatol. 2017;16(5):496-500.

22. Food U, Administration D The FDA warns that biotin may interfere with lab tests: FDA safety communication.2018.

23. Dawber R, Rundegren J. Hypertrichosis in females applying minoxidil topical solution and in normal controls. J Eur Acad Dermatol Venereol. 2003;17(3):271-275. doi:10.1046/j.1468-3083.2003.00621.x

24. Friedman ES, Friedman PM, Cohen DE, Washenik K. Allergic contact dermatitis to topical minoxidil solution: etiology and treatment. $J \mathrm{Am}$ Acad Dermatol. 2002;46(2):309-312. doi:10.1067/mjd.2002.119104

25. Nalluri R, Harries M. Alopecia in general medicine. Clin Med. 2016;16(1):74-78. doi:10.7861/clinmedicine.16-1-74

26. Majeed M, Badmaev V Method of preparation and use of coconut water in mamalian tissue nourishment growth and healthy maintenance. US Patent 7,300,682. 2007.

27. Majeed M Compositions and methods to treat alopecia. US Patent Application 12/060,558 2008.

28. Majeed M, Nagabhushanam K, Bhat B, Kanhangad-Gangadharan G, Anand-Tathapudi S, Paliwal P Protective compositions for dermal papilla cells. US Patent 8,247,003, 2012.

29. Majeed M, Nagabhushanam K Synergistic selenopeptide formulations for the protection of dermal papilla cells. US Patent 9,498,423, 2016.

30. Jain PK, Das D, Pandey N, Jain P. Traditional Indian herb Emblica officinalis and its medicinal importance. Innov $J$ Ayurvedic Sci. 2016;4(4):1-15.

31. Yu JY, Gupta B, Park HG, et al. Preclinical and clinical studies demonstrate that the proprietary herbal extract DA-5512 effectively stimulates hair growth and promotes hair health. Evid Based Complementary Alter Med. 2017;2017.
32. Goluch-Koniuszy ZS. Nutrition of women with hair loss problem during the period of menopause. Prz Menopauzalny. 2016;15 (1):56-61. doi:10.5114/pm.2016.58776

33. Vala G, Kapadiya P. Medicinal benefits of coconut oil. Int J Life Sci Res. 2014;2(4):124-126.

34. Adhikari B, Dhungana SK, Ali MW, Adhikari A, Kim I-D, Shin D-H. Antioxidant activities, polyphenol, flavonoid, and amino acid contents in peanut shell. J Saudi Soc Agri Sci. 2019;18(4):437-442. doi:10.1016/j.jssas.2018.02.004

35. Fernandez E, Martinez-Teipel B, Armengol R, Barba C, Coderch L. Efficacy of antioxidants in human hair. $J$ Photochem Photobiol B. 2012;117:146-156. doi:10.1016/j.jphotobiol.2012.09.009

36. Majeed M, Prakash L. Tetrahydropiperine: A Natural Topical Permeation Enhancer. In: Delivery System Handbook for Personal Care and Cosmetic Products. Elsevier. 2005:157-178.

37. Majeed M, Badmaev V, Bammi RK, Prakash S, Natarajan S Method of increased bioavailability of nutrients and pharmaceutical preparations with tetrahydropiperine and its analogues and derivatives. US Patent 6,849,645, 2005.

38. Majeed M, Nagabhushanam K, Ramanujam R, Chandramouli RH Dipeptides incorporating selenoamino acids with enhanced bioavailability — synthesis, pharmaceutical and cosmeceutical applications thereof. US Patent 8,003,614, 2011.

39. Rogers NE, Avram MR. Medical treatments for male and female pattern hair loss. J Am Acad Dermatol. 2008;59(4):547-566. (). doi:10.1016/j.jaad.2008.07.001

40. Semalty M, Semalty A, Joshi GP, Rawat MS. Hair growth and rejuvenation: an overview. $J$ Dermatolog Treat. 2011;22 (3):123-132. doi:10.3109/09546630903578574

41. Ozeki M, Tabata Y. Promoted growth of murine hair follicles through controlled release of vascular endothelial growth factor. Biomaterials. 2002;23(11):2367-2373. doi:10.1016/S0142-9612(01)00372-6

42. Sharma L, Agarwal G, Kumar A. Medicinal plants for skin and hair care. Indian J Trad Knowledge. 2003;2(1):62-68.

43. Khan KH. Roles of Emblica officinalis in medicine-A review. Bot Res Int. 2009;2(4):218-228.

44. Thomas MB, Khan K, Sharma S, Singh L, Upadhyay M. In vitro evaluation of anti-microbial and anti-oxidant activity of Emblica officinalis juice powder. Adv Pharmacol Pharm. 2013;1:9-12.

45. Rushton D. Nutritional factors and hair loss. Clin Exp Dermatol. 2002;27(5):396-404. doi:10.1046/j.1365-2230.2002.01076.x

46. Majeed M, Vaidyanathan P News from Sabinsa on Hair Care. https:// www.researchgate.net/publication/283992618_News_from_Sabinsa_ in_Hair_care.

47. Marzani B, Pinto D, Sorbellini E, Rinaldi F. New multi-targeting strategy in hair growth promotion: in vitro and in vivo studies. G Ital Dermatol Venereol. 2018;153(3):338-343. doi:10.23736/S03920488.18.05891-1

48. Price VH, Menefee E, Sanchez M, Ruane P, Kaufman KD. Changes in hair weight and hair count in men with androgenetic alopecia after treatment with finasteride, $1 \mathrm{mg}$, daily. $J$ Am Acad Dermatol. 2002;46 (4):517-523. doi:10.1067/mjd.2002.120537

49. Wee J-H, Moon J-H, Eun J-B, Chung J-H, Kim Y-G, Park K-H. Isolation and identification of antioxidants from peanut shells and the relationship between structure and antioxidant activity. Food Sci Biotechnol. 2007;16(1):116-122.

50. Seelinger G, Merfort I, Schempp CM. Anti-oxidant, anti-inflammatory and anti-allergic activities of luteolin. Planta Med. 2008;74(14):1667-1677. doi:10.1055/s-0028-1088314 


\section{Publish your work in this journal}

Clinical, Cosmetic and Investigational Dermatology is an international, peer-reviewed, open access, online journal that focuses on the latest clinical and experimental research in all aspects of skin disease and cosmetic interventions. This journal is indexed on CAS.
The manuscript management system is completely online and includes a very quick and fair peer-review system, which is all easy to use. Visit http://www.dovepress.com/testimonials.php to read real quotes from published authors.

Submit your manuscript here: https://www.dovepress.com/clinical-cosmetic-and-investigational-dermatology-journal 